\title{
Seismic behavior of buried pipelines constructed by design criteria and construction specifications of both Korea and the US
}

\author{
S.-S. Jeon \\ Correspondence to: S.-S. Jeon (ssj@inje.ac.kr) \\ Received: 19 January 2013 - Published in Nat. Hazards Earth Syst. Sci. Discuss.: 5 March 2013 \\ Revised: 6 August 2013 - Accepted: 6 August 2013 - Published: 13 September 2013
}

School of Civil \& Urban Engineering, Construction Technology Research Center, INJE University, Kimhae, South Korea

\begin{abstract}
Earthquake loss estimation systems in the US, for example HAZUS (Hazard in US), have been established based on sufficient damage records for the purpose of prevention and efficient response to earthquake hazards; however, in Korea, insufficient data sets of earthquakes and damage records are currently available. In this study, the earthquake damages to pipelines in Korea using the pipeline repair rate (RR) recommended in HAZUS was reevaluated with the degree of confidence when RR is used without modification for the damage estimation of pipelines in Korea. The numerical analyses using a commercial finite element model, ABAQUS, were carried out to compare stresses and strains mobilized in both brittle and ductile pipelines constructed by the design criteria and construction specifications of both Korea and the US. These pipelines were embedded in dense sand overlying three different in situ soils (clay, sand, and gravel) subjected to earthquake excitations with peak ground accelerations (PGAs) of 0.2 to $1.2 \mathrm{~g}$ and 1994 Northridge and 1999 Chi-Chi earthquake loadings. The numerical results show that differences in the stress and strain rates are less than $10 \%$. This implies that RR in HAZUS can be used for earthquake damage estimation of pipelines with a $90 \%$ confidence level in Korea.
\end{abstract}

\section{Introduction}

Buried pipelines, one example of lifelines, have not been damaged by previous earthquakes in Korea. However, vibrations of the ground and buildings were perceived by people living in both Busan and Masan, located in the southern part of Korea, during the 2005 Fukuoka earthquake that occurred in Japan (Park et al., 2005). In recent years, earthquakes have become frequent in Korea and thus the behavior of buried pipelines subjected to seismic loading is examined in this paper.

There have been a number of studies related to buried pipelines. For example, Wang and Cheng (1979) performed a simplified quasi-static seismic deformation analysis for buried pipelines subjected to earthquake loadings to examine the effects of seismic parameters. They found that the behavior of buried pipeline was dominantly influenced by the time delay of seismic waves and the nonuniformity of soil resistance.

Takada and Tanabe (1987) developed a three-dimensional quasi-static numerical analysis of continuous or jointed pipelines subject to large ground deformations or seismic ground motions. The wave propagation hazard for a particular site is characterized by the peak ground motion parameters as well as the appropriate propagation velocities.

O'Rourke and Liu (1999) analyzed the ground strain and curvature due to wave propagation and discussed the influence of various subsurface conditions on ground strain. Transient ground strains are recognized to govern the response of buried elongated structures, such as pipelines and tunnels, under seismic wave propagation.

Scandella and Paolucci (2010) investigated the shear strain and the longitudinal strain variability with depth through qualitative examples and comparisons with analytical formulas. In Korea, Lee et al. (2009) performed earthquake time-history analyses for a buried gas pipeline using various parameters such as the type of buried gas pipeline, end restrain conditions, soil characteristics, single and multiple earthquake input ground motions, and burial depths.

Buried pipeline damage correlations are a critical component of loss estimation procedures applied to lifelines 
Table 1. Brittle and ductile pipelines classified by pipe materials (Ministry of Environment, 2010a, b).

\begin{tabular}{ll}
\hline Types of pipeline & Pipe materials \\
\hline Ductile & $\begin{array}{l}\text { Ductile iron, steel, galvanized steel, polyethylene, stainless steel, copper, } \\
\text { polyethylene sheeting, fiber reinforced }\end{array}$ \\
Brittle & $\begin{array}{l}\text { Steel reinforced concrete, cast iron, earthen, centrifugal reinforced concrete, } \\
\text { lime cast iron, steel reinforced concrete box, Hume concrete }\end{array}$ \\
\hline
\end{tabular}

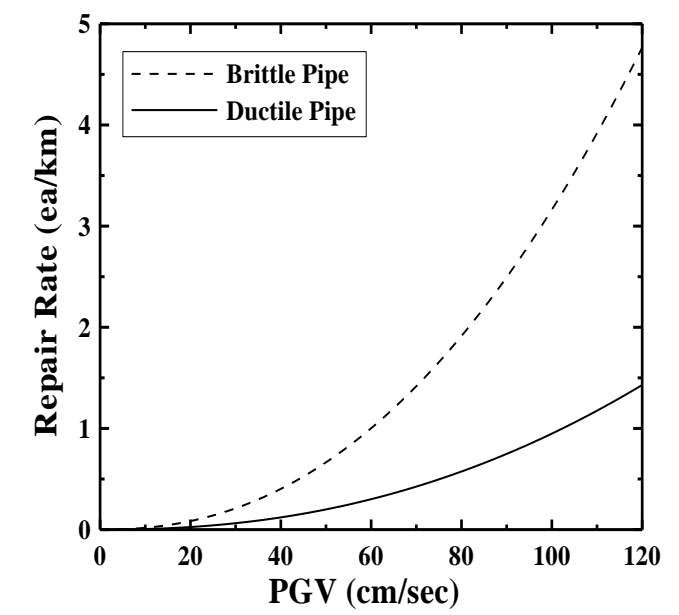

Fig. 1. Fragility curve of buried pipelines provided by HAZUS with the RR given as a function of the PGV (FEMA, 1999).

expected to experience future earthquakes. Buried pipelines are damaged by transient ground motions and permanent ground deformation. Pipeline damage induced by wave propagation for relatively flexible pipe materials was found to be somewhat less than damage of relatively brittle material (O'Rourke and Ayala, 1993). Permanent ground deformation and its effect on pipelines has been extensively investigated (O'Rourke et al., 1998), especially in countries of high seismicity. During representative earthquakes, including the Loma Prieta earthquake in 1989, buried pipelines were damaged mostly in landfill areas by means of joint pullout failures and pipeline cracking. In addition to these damage patterns, artificial connections between relatively rigid pipelines and largely deformable plastic pipe experienced damage during the Kobe earthquake in 1995. Trunk pipeline damage and cracks in the axial direction of concrete pipelines were assessed. Pipeline repair rates (RRs) following the 1994 Northridge earthquake were evaluated and explained (Jeon, 2002; Jeon and O'Rourke, 2005).

Shih and Chang (2006) performed a seismic fragility analysis of underground polyvinyl chloride (PVC) pipelines and demonstrated that there was no significant difference between the analyses results and the empirical equation used by HAZUS (Hazard in US), i.e., earthquake loss estimation software developed by the Federal Emergency Management Agency (FEMA).
Table 2. Required minimum embedded depth for buried pipeline as loading is applied to ground surface (Ministry of Land, Transport, and Maritime Affairs, 2010).

\begin{tabular}{ll}
\hline $\begin{array}{l}\text { Pipeline } \\
\text { diameter }(D)\end{array}$ & $\begin{array}{l}\text { Required minimum } \\
\text { embedded depth }(\mathrm{mm})\end{array}$ \\
\hline$D \leq 900 \mathrm{~mm}$ & $1200 \mathrm{~mm}$ \\
$D \geq 1000 \mathrm{~mm}$ & $D \leq$ and $\geq 1500 \mathrm{~mm}$ \\
\hline
\end{tabular}

Table 3. Minimum embedded depth for buried pipeline (Office of Pipeline Safety Community (OPS), 2010).

\begin{tabular}{lr}
\hline Location & $\begin{array}{r}\text { Embedded depth for } \\
\text { normal excavation (mm) }\end{array}$ \\
\hline Industrial and residential areas & 914 \\
$30 \mathrm{~m}$ width stream & 1219 \\
Public roadway and railway ditch & 914 \\
Port areas in deep water & 1219 \\
Mexico Bay and water depth (ebb tide) $\leq 4.6 \mathrm{~m}$ & 914 \\
Water depth (ebb tide) $\leq 3.6 \mathrm{~m}$ & 914 \\
Other areas & 762 \\
\hline
\end{tabular}

Toprak and Taskin (2007) estimated pipeline damage for each damage relationship and earthquake scenario. The results show that the variation in ductile pipeline damage estimations by various relationships was higher than the variation in brittle pipeline damage estimations for a particular scenario earthquake. Pineda-Porras and Ordaz (2007) proposed a new seismic intensity parameter utilizing peak ground velocity (PGV) and peak ground acceleration (PGA) to estimate damage in buried pipelines due to seismic wave propagation.

Tan and Chen (1987) estimated the probability of system serviceability as the ratio of the number of networks that were found to be serviceable to the sample size used for simulation. The water transmission network was adopted and analyzed to serve as a numerical example demonstrating how to assess the probabilities of system unserviceability under a set of assumed parameter values deemed reasonable. Filho et al. (2010) developed a decision support system for the management of geotechnical and environmental risks in oil pipelines using GIS.

Historical data and recorded data sets after 1905 show that Korea is in a zone of low to medium seismicity but it has a high frequency of earthquake occurrences. In this study, 
Table 4. Mechanical characteristics of soils used in numerical analysis.

\begin{tabular}{lrrrrr}
\hline $\begin{array}{l}\text { Soil } \\
\text { types }\end{array}$ & $\begin{array}{r}\gamma \\
\left(\mathrm{kN} \mathrm{m}^{-3}\right)\end{array}$ & $\begin{array}{r}E \\
(\mathrm{MPa})\end{array}$ & $v$ & $\begin{array}{r}c \\
(\mathrm{kPa})\end{array}$ & $\begin{array}{r}\varphi \\
\left({ }^{\circ}\right)\end{array}$ \\
\hline Clay & 15.0 & 5 & 0.35 & 10 & 20 \\
Loose sand & 18.6 & 15 & 0.3 & 0 & 25 \\
Medium dense sand & 19.0 & 25 & 0.3 & 0 & 28 \\
Dense sand & 19.4 & 45 & 0.3 & 0 & 30 \\
Dense sand and gravel & 20.0 & 120 & 0.25 & 0 & 35 \\
\hline
\end{tabular}

pipelines were classified by their mechanical properties followed by a numerical analysis which examined the behavior of the buried pipelines constructed by the design criteria and construction specifications of Korea and the US. The analysis considered seismic parameters including PGA achieved from previous earthquake records, pipeline types, and in situ ground conditions.

This paper is organized as follows. First, the repair rate (RR) of pipelines (Sect. 2) is described based on historical literature review. Second, the design criteria and construction specifications (Sect. 3) are examined for the pipelines in both Korea and the US. Then, a dynamic behavior of the pipeline using numerical analysis (Sect. 4) is evaluated by using the commercial finite element software ABAQUS (2006).

\section{Repair rate of pipelines}

The damages of water pipelines in HAZUS were assessed by historical data of pipeline repairs from previous earthquakes. As shown in Fig. 1, the algorithm of RR for brittle and ductile pipelines in HAZUS was developed by O'Rourke and Ayala (1993). They developed the empirical relationship of RR with PGV based on the damage reports of the pipelines from previous earthquakes (FEMA, 1999).

Since the mechanical characteristics of pipelines, design criteria, and construction specifications of both Korea and the US are very similar, the pipeline damages induced by seismic loadings in Korea has been predicted by RR suggested in HAZUS. As the seismic loading was applied to buried pipelines constructed based on the design criteria and construction specifications in Korea and the US, the mobilized stresses and strain rates of pipelines were examined and compared.

As listed in Table 1, buried utilities in Korea, including water, gas, and communication pipelines, were classified into two categories; ductile and brittle (Ministry of Environment, 2010a, b).

\section{Design criteria and construction specifications}

The burial depth, the backfill compaction ratio, and the diameter and thickness of pipelines listed on the construction

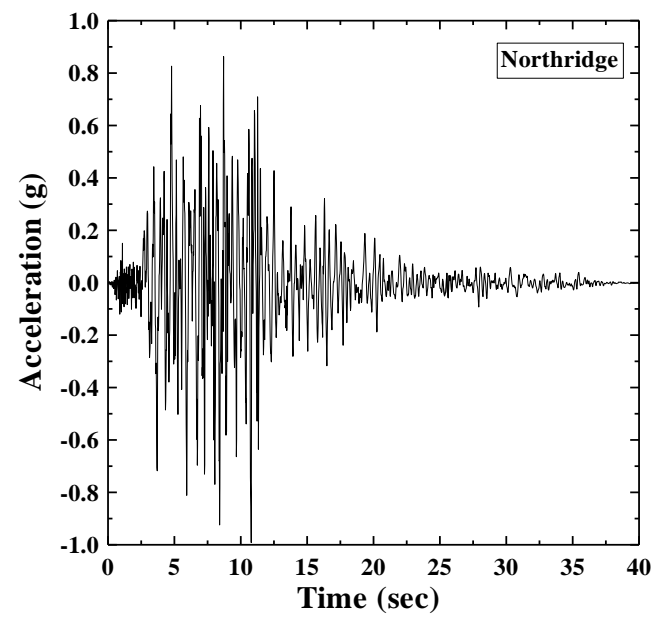

Fig. 2. History of ground acceleration record during the 17 January 1994 Northridge $\left(M_{\mathrm{W}}=6.7\right)$ earthquake (COSMOS, 2010).

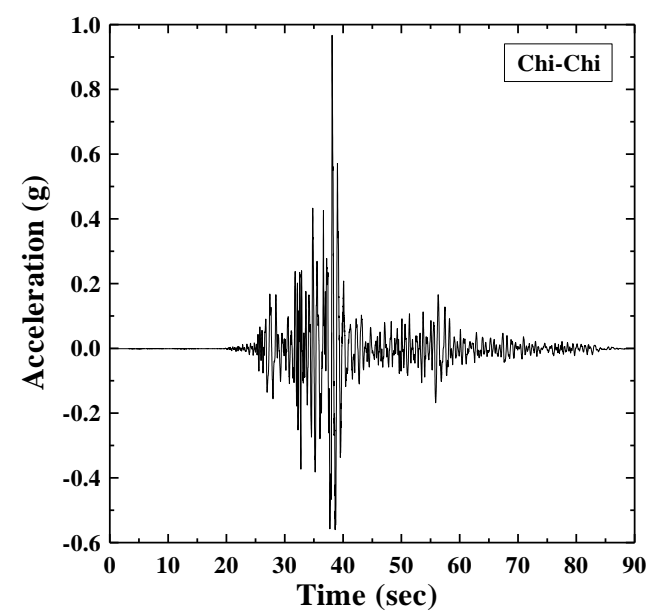

Fig. 3. History of ground acceleration record during the 21 September 1999 Chi-Chi $\left(M_{\mathrm{w}}=7.6\right)$ earthquake (COSMOS, 2010).

specifications were used in a numerical analysis to examine the dynamic behavior of pipelines as seismic loading was applied.

\subsection{Korea}

As listed in Table 2, the burial depths, considering traffic loading, should be greater than 1.2 and $1.5 \mathrm{~m}$ for the 900 and $1000 \mathrm{~mm}$ diameter pipelines, respectively (Ministry of Land, Transport, and Maritime Affairs, 2010). The burial depth for large diameter pipelines should be greater than their diameter but, in the case that a burial depth of $1.2 \mathrm{~m}$ is not available due to spatial constraints associated with adjacent underground structures, the burial depth can be reduced to $0.6 \mathrm{~m}$ with permission from the officer in charge of roadway management (Ministry of Land, Transport, and Maritime Affairs, 2010). 
Table 5. Mechanical characteristics of pipelines used in numerical analysis.

\begin{tabular}{lrrc}
\hline $\begin{array}{l}\text { Types of } \\
\text { pipelines }\end{array}$ & $\begin{array}{r}\gamma \\
\left(\mathrm{kN} \mathrm{m}^{-3}\right)\end{array}$ & $\begin{array}{r}E \\
(\mathrm{MPa})\end{array}$ & $v$ \\
\hline Ductile & 69.1 & 160000 & 0.28 \\
Brittle & 22.5 & 19600 & 0.17 \\
\hline
\end{tabular}

\subsection{The US}

Table 3 lists the specifications for the burial depth of pipelines with respect to construction sites where there are no special conditions (Office of Pipeline Safety Community (OPS), 2010). Pipeline burial depth should be greater than the frozen ground depth or frost line. High quality soil is used as backfill material for buried pipelines. Each layer of backfill should have a thickness less than $0.3 \mathrm{~m}$ and a compaction ratio of greater than $90 \%$ and, at important construction sites, the water content of backfill materials should be around the optimum water content and at most $0.2 \mathrm{~m}$ lifts with high compaction ratios are required (OPS, 2010). Sands used as trench backfill material should have a high compaction ratio with moisture near the optimum water content and the use of soil lifts is recommended (OPS, 2010).

Lift thicknesses of $20-50 \%$ of the minimum diameter of a pipeline are required in Korea (Ministry of Land, Transport, and Maritime Affairs, 2010). A lift thickness corresponding to one-eighth of the minimum diameter of the pipeline or $100 \mathrm{~mm}$ is required in the US (OPS, 2010).

\section{Evaluating dynamic behavior of the pipeline using numerical analysis}

In this study, a numerical analysis using the commercial finite element software ABAQUS (2006) was carried out to analyze the dynamic behavior of pipelines subjected to seismic loading. The analysis's results show the strain rates and stresses of buried pipelines constructed by the design criteria and construction specifications suggested by both Korea and the US. The applied seismic loadings were generated from real PGV time records measured at strong motion stations (SMSs) No. 24436 and CHY080 for the 1994 Northridge $\left(M_{\mathrm{W}}=6.7\right)$ and 1999 Chi-Chi $\left(M_{\mathrm{w}}=7.6\right)$ earthquakes, respectively. Figures 2 and 3 show the measured PGV time records of Northridge and Chi-Chi earthquakes, respectively (COSMOS, 2010). In addition to these, the virtual values of various PGAs, such as $0.2,0.4,0.6,0.8,1.0$, and $1.2 \mathrm{~g}$, at a period of $0.5 \mathrm{~s}$ and earthquake duration of $10 \mathrm{~s}$ were applied as seismic loadings. Numerical modeling will first be examined, followed by dynamic behavior of the pipeline.

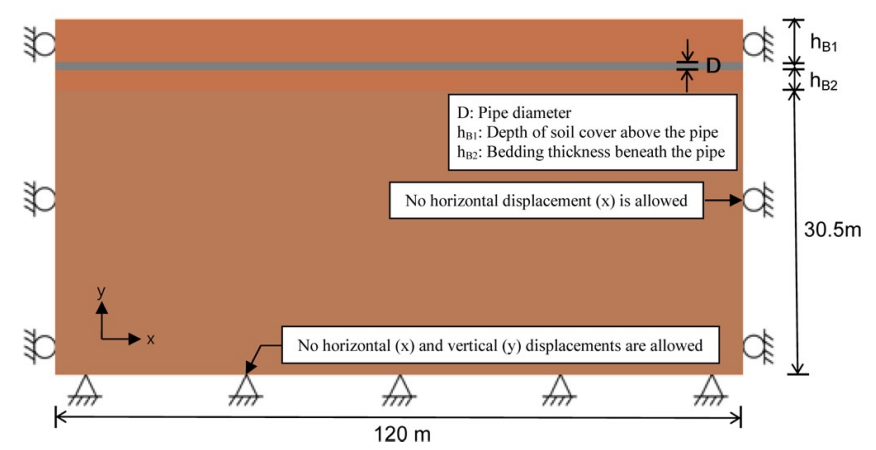

Fig. 4. Configuration of numerical model associated with pipeline and an in situ soil depth and width of 30.5 and $120 \mathrm{~m}$, respectively.

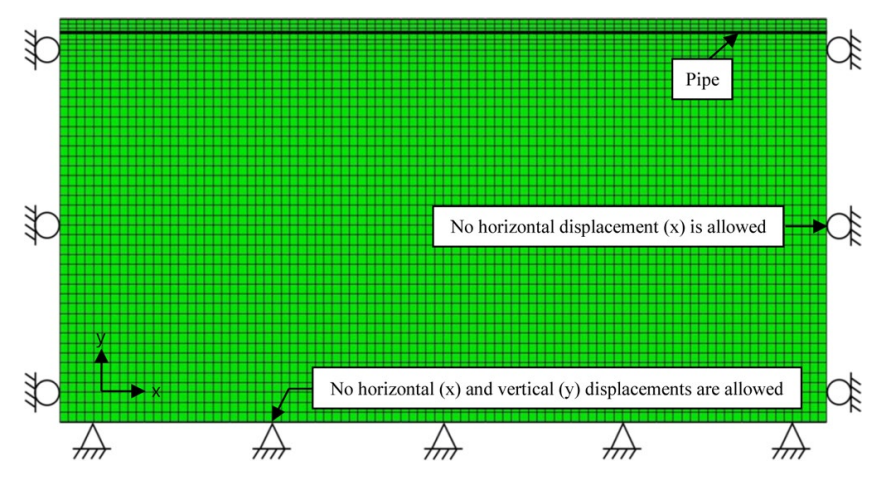

Fig. 5. Finite element mesh configuration and boundary conditions for pipelines and an in situ soil depth and width of 30.5 and $120 \mathrm{~m}$, respectively.

\subsection{Numerical modeling}

The numerical analyses for brittle and ductile pipelines with a greater than $1000 \mathrm{~mm}$ diameter and constructed based on the design criteria and construction specifications of both Korea and the US were carried out. Since a compaction ratio of $90 \%$ for backfill materials is required in both countries, dense sand soil properties were used. The analyses were performed considering various in situ ground conditions such as clay, loose sand, medium dense sand, dense sand, and sand with gravel. In Korea, the diameter and thickness of the brittle and ductile pipelines used in the analyses were 1050 and $75 \mathrm{~mm}$ and 1130 and $16 \mathrm{~mm}$, respectively. For the US, these values were 1058 and $75 \mathrm{~mm}$ and 1144 and $16 \mathrm{~mm}$, respectively.

Figures 4 and 5 show the configuration and finite difference meshes of numerical analysis associated with pipeline, ground conditions, and boundary conditions. The figure shows an in situ soil depth of $30.5 \mathrm{~m}$ with a $120 \mathrm{~m}$ width ground. No horizontal displacements are allowed at the left and right sides and no horizontal nor vertical displacements are allowed at the bottom. In Korea and the US, a depth of soil cover above the pipe $\left(h_{B 1}\right)$ of 1.5 and $0.9 \mathrm{~m}$ and a bedding thickness beneath the pipe $\left(h_{B 2}\right)$ of 0.25 and $0.15 \mathrm{~m}$, 
Table 6. Mobilized strain difference (\%) of pipeline modeled based on Korea and US design criteria and construction specification.

\begin{tabular}{|c|c|c|c|c|c|c|c|c|c|}
\hline Pipe & Soil $\backslash$ PGA (g) & 0.2 & 0.4 & 0.6 & 0.8 & 1.0 & 1.2 & $\operatorname{Avg}^{1}$ & $\mathrm{SD}^{2}$ \\
\hline \multirow{5}{*}{ Ductile pipe } & Clay & 8.8 & 8.6 & 8.7 & 8.9 & 8.3 & 6.4 & 8.3 & 0.94 \\
\hline & Loose sand & 9.8 & 9.8 & 8.3 & 8.5 & 7.8 & 7.4 & 8.6 & 1.02 \\
\hline & Medium dense sand & 9.7 & 8.7 & 8.6 & 7.9 & 4.8 & 7.7 & 7.9 & 1.65 \\
\hline & Dense sand & 9.1 & 6.1 & 5.0 & 6.3 & 6.2 & 3.5 & 6.1 & 1.85 \\
\hline & Dense sand and gravel & 8.8 & 4.8 & 5.0 & 4.6 & 4.6 & 4.5 & 5.4 & 1.69 \\
\hline \multirow{5}{*}{ Brittle pipe } & Clay & 8.5 & 8.5 & 4.9 & 4.4 & 3.8 & 6.0 & 6.0 & 2.09 \\
\hline & Loose sand & 8.8 & 9.9 & 6.0 & 3.0 & 3.1 & 4.1 & 5.8 & 2.97 \\
\hline & Medium dense sand & 8.9 & 7.5 & 5.2 & 3.1 & 3.0 & 2.8 & 5.1 & 2.62 \\
\hline & Dense sand & 9.9 & 9.3 & 8.0 & 4.4 & 2.2 & 3.3 & 6.2 & 3.28 \\
\hline & Dense sand and gravel & 9.8 & 6.7 & 8.0 & 4.2 & 5.3 & 5.4 & 6.5 & 2.06 \\
\hline
\end{tabular}

${ }^{1}$ Avg: average; ${ }^{2}$ SD: standard deviation.

Table 7. Mobilized stress difference (\%) of pipeline modeled based on Korea and US design criteria and construction specification.

\begin{tabular}{llrrrrrrrr}
\hline Pipeline & Soil $\backslash$ PGA (g) & 0.2 & 0.4 & 0.6 & 0.8 & 1.0 & 1.2 & Avg & SD $^{2}$ \\
\hline \multirow{5}{*}{ Ductile pipe } & 11.3 & 8.8 & 5.2 & 7.2 & 5.7 & 4.7 & 7.2 & 2.53 \\
& Clay & 11.8 & 9.7 & 7.1 & 5.9 & 4.9 & 4.7 & 7.3 & 2.84 \\
& Loose sand & 10.1 & 7.9 & 9.3 & 5.9 & 6.3 & 4.7 & 7.4 & 2.10 \\
& Dedium dense sand & 11.7 & 9.2 & 4.1 & 5.9 & 2.9 & 2.6 & 6.1 & 3.69 \\
& Dense sand & 10.7 & 4.6 & 5.9 & 5.4 & 6.1 & 3.9 & 6.1 & 2.39 \\
\hline \multirow{5}{*}{ Brittle pipe and gravel } & Clay & 8.0 & 9.3 & 7.2 & 7.5 & 5.6 & 4.2 & 7.0 & 1.82 \\
& Loose sand & 7.2 & 9.3 & 6.4 & 6.6 & 5.1 & 4.4 & 6.5 & 1.73 \\
& Medium dense sand & 7.8 & 6.1 & 6.3 & 6.4 & 4.8 & 4.7 & 6.0 & 1.15 \\
& Dense sand & 7.0 & 9.1 & 8.0 & 6.5 & 6.8 & 4.7 & 7.0 & 1.49 \\
& Dense sand and gravel & 6.9 & 7.5 & 8.2 & 4.9 & 6.7 & 7.1 & 6.9 & 1.08 \\
\hline
\end{tabular}

${ }^{1}$ Avg: average; ${ }^{2}$ SD: standard deviation.

respectively, were used in numerical analysis. Tables 4 and 5 list the mechanical properties of the soils and pipelines, respectively.

\subsection{Dynamic behavior of the pipeline}

\subsubsection{Ductile pipeline}

Figure 6 shows the maximum mobilized stress for ductile pipeline subjected to various ground conditions As shown in the figure, the mobilized stress in pipelines linearly increases as PGA increases and ground stiffness decreases. The mobilized stress of pipelines in Korea relative to the US is slightly smaller. Differences mobilized along the pipelines range from 4.7 to $11.3 \%, 4.7$ to $11.8 \%, 4.7$ to $10.1 \%, 2.6$ to $11.7 \%$, and 3.9 to $10.7 \%$ for in situ ground conditions of clay, loose sand, medium dense sand, dense sand, and dense sand with gravel, respectively.

Figure 7 shows the maximum strain mobilized on ductile pipelines for various ground conditions. As shown in the figure, the strain rate mobilized along the pipelines increases as PGA increases and ground stiffness decreases. The strain rate of pipeline in Korea relative to the US is slightly higher.
The strain rates differ from 6.4 to $8.9 \%, 7.4$ to $9.8 \%, 4.8$ to $9.7 \%, 3.5$ to $9.1 \%$, and 4.5 to $8.8 \%$ for in situ ground conditions of clay, loose sand, medium dense sand, dense sand, and dense sand with gravel, respectively. As the seismic loadings of Northridge and Chi-Chi earthquakes were applied, the mobilized pipeline strains were 1.9 and $4.5 \%$, respectively.

\subsubsection{Brittle pipeline}

Figure 8 shows the maximum mobilized stress for brittle pipeline subjected to various ground conditions. As shown in the figure, stresses in pipelines linearly increase as PGA increases and ground stiffness decreases. The mobilized stress of pipelines in Korea, relative to the US, is slightly smaller. Stress differences mobilized along pipelines range from 4.2 to $9.3 \%, 4.4$ to $9.3 \%, 4.7$ to $7.8 \%, 4.7$ to $9.1 \%$, and 4.9 to $8.2 \%$ for in situ ground conditions of clay, loose sand, medium dense sand, dense sand, and dense sand with gravel, respectively.

Figure 9 shows the maximum mobilized strain for brittle pipeline subjected to various ground conditions. As shown in the figure, strain rates mobilized along pipeline increase as the PGA increases and ground stiffness decreases. The 


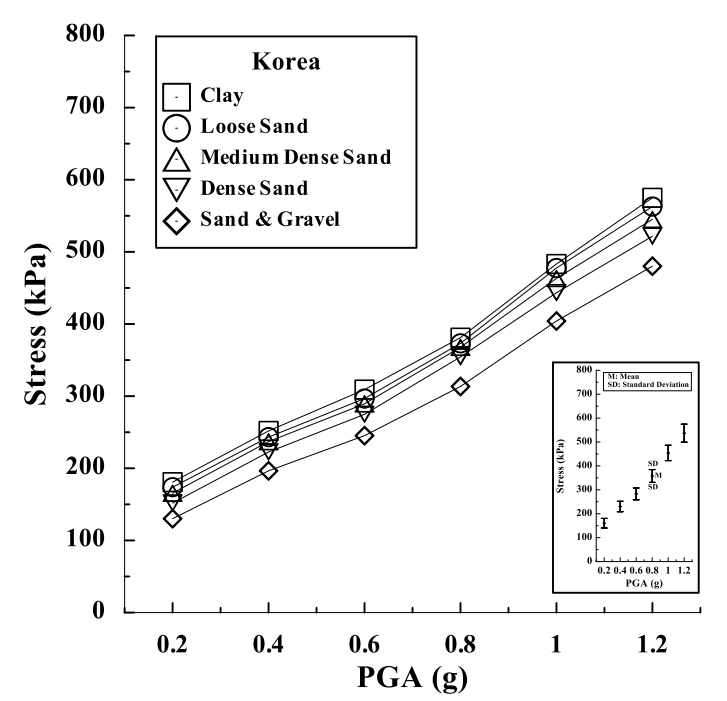

(a) Korea

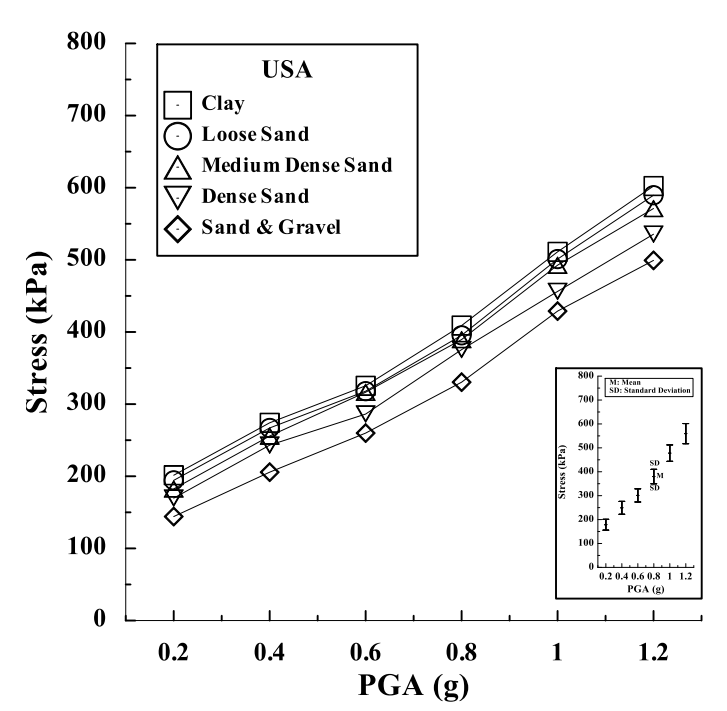

(b) The US

Fig. 6. Stress of ductile pipeline mobilized by earthquake loadings with respect to PGA in various in situ ground conditions. Values are derived from finite element analysis (see Fig. 5 and Sect. 4.2.1 for further details).

pipeline strain rate in Korea relative to the US is smaller. Strain differences mobilized along pipelines range from 3.8 to $8.5 \%, 3.0$ to $9.9 \%, 2.8$ to $8.9 \%, 2.2$ to $9.9 \%$, and 4.5 to $9.8 \%$ for in situ ground conditions of clay, loose sand, medium dense sand, dense sand, and dense sand with gravel, respectively. As the seismic loadings of Northridge and ChiChi earthquakes were applied, the generated strains were 6.5 and $3.8 \%$, respectively.

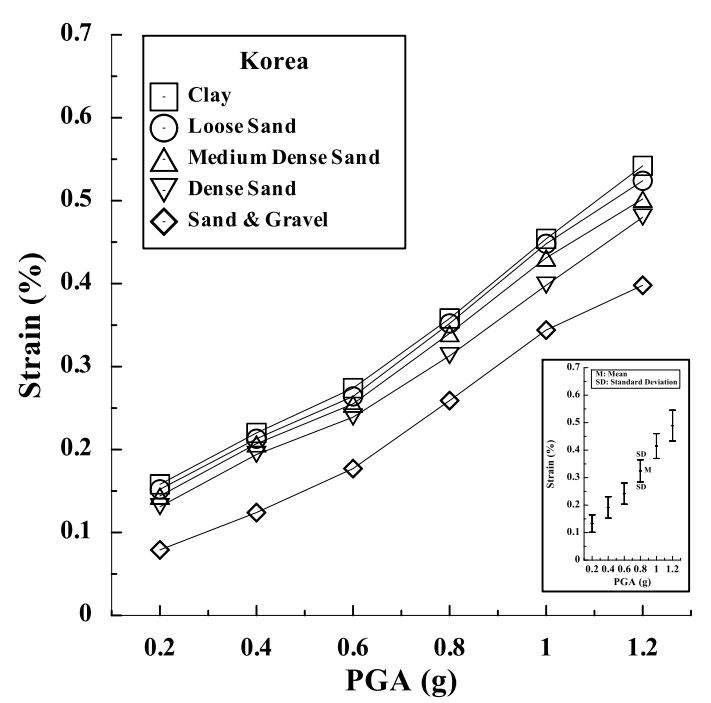

(a) Korea

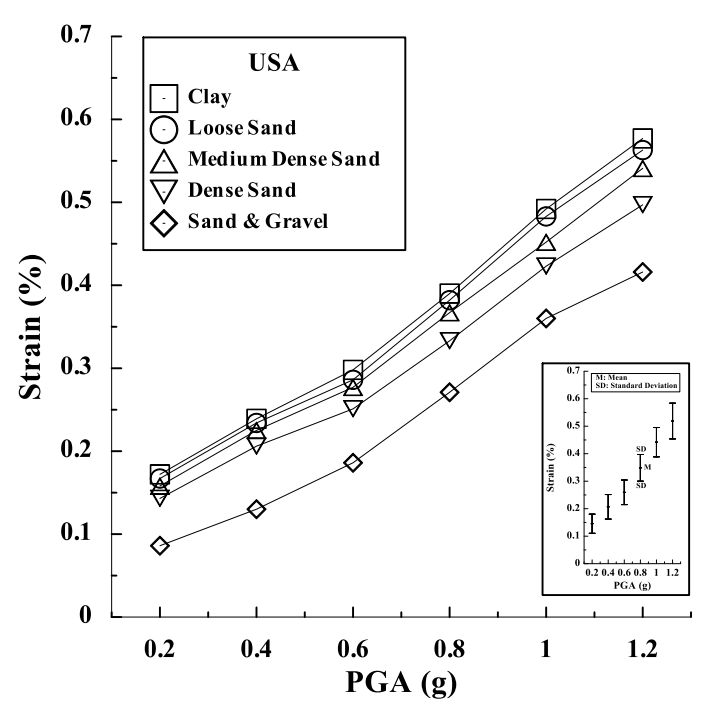

(b) The US

Fig. 7. Strain (\%) of ductile pipeline mobilized by earthquake loadings with respect to PGA in various in situ ground conditions. Values are derived from finite element analysis (see Fig. 5 and Sect. 4.2.1 for further details).

Tables 6 and 7 present the differences of the strain and stress, calculated by using Eqs. (1) and (2), respectively:

$\varepsilon_{\text {diff }}=\frac{\varepsilon_{\mathrm{k}}-\varepsilon_{\mathrm{u}}}{\varepsilon_{\mathrm{k}}} \times 100(\%)$,
$\sigma_{\text {diff }}=\frac{\sigma_{\mathrm{k}}-\sigma_{\mathrm{u}}}{\sigma_{\mathrm{k}}} \times 100(\%)$,

where $\varepsilon_{\text {diff }}$ represents difference of strain mobilized in Korea and US pipelines, $\varepsilon_{\mathrm{k}}$ represents strain mobilized in Korea pipeline, $\varepsilon_{\mathrm{u}}$ represents strain mobilized in US pipeline, $\sigma_{\text {diff }}$ represents difference of stress mobilized in Korea and US 


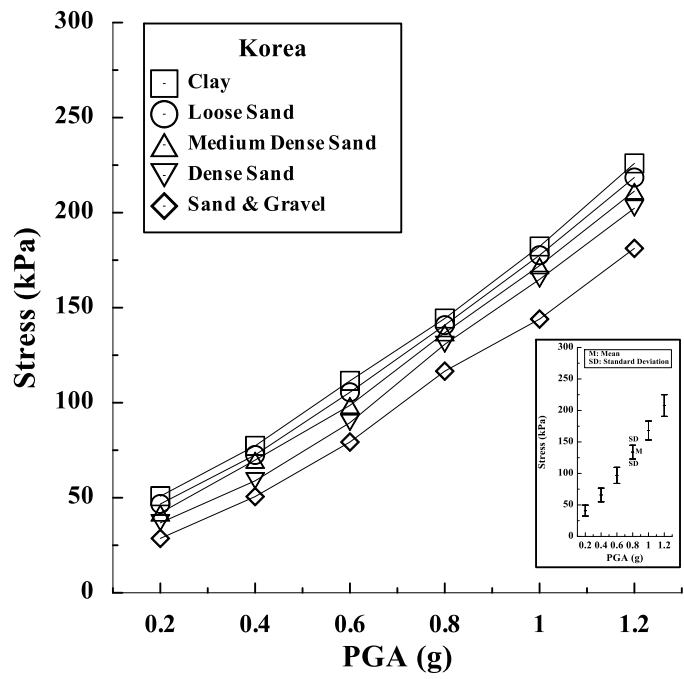

(a) Korea

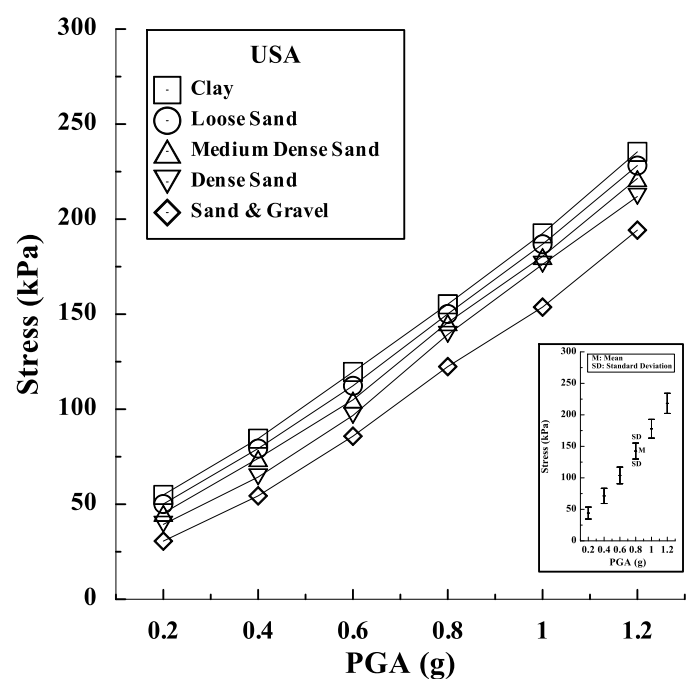

(b) The US

Fig. 8. Stress of brittle pipeline mobilized by earthquake loadings with respect to PGA in various in situ ground conditions. Values are derived from finite element analysis (see Fig. 5 and Sect. 4.2.2 for further details).

pipelines, $\sigma_{\mathrm{k}}$ represents stress mobilized in Korea pipeline, and $\sigma_{\mathrm{u}}$ represents stress mobilized in US pipeline.

The results show that differences of stress and strain mobilized along the pipelines in Korea and the US are 6 to $7.4 \%$ and 6 to $8.6 \%$ with standard deviations of 1.08 to 3.69 and of 0.94 to 3.28 , respectively. Differences of both stress and strain mobilized along the pipelines in Korea and US are less than $10 \%$. Based on the analyses results, RR in HAZUS can be used for the earthquake damage estimation of pipelines in Korea with a $90 \%$ confidence level.

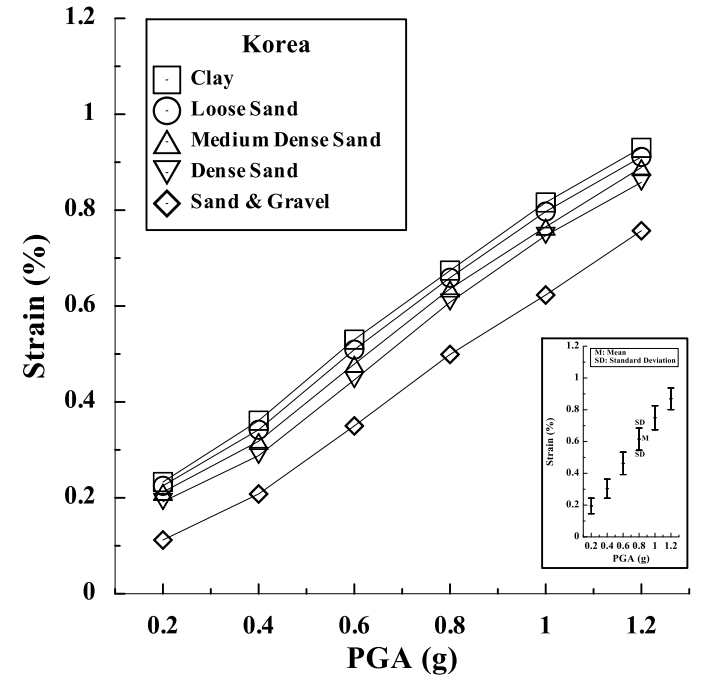

(a) Korea

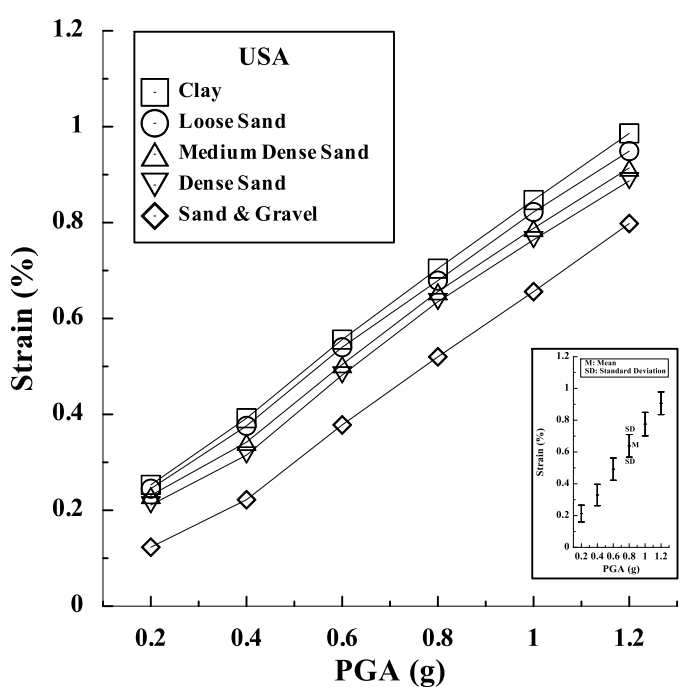

(b) The US

Fig. 9. Strain (\%) of brittle pipeline mobilized by earthquake loadings with respect to PGA in various in situ ground conditions. Values are derived from finite element analysis (see Fig. 5 and Sect. 4.2.2 for further details).

\section{Conclusions}

The objective of this study is to examine the confidence level when RR recommended in HAZUS is directly used for the damage estimation of pipelines in Korea due to seismic loading. RR in HAZUS was developed based on historical data of high magnitude earthquakes in the US. There is deficient or no historical data available for pipelines damaged by earthquakes in Korea. Therefore, as an approximate earthquake damage estimation of pipelines, RR recommended in HAZUS can be used for the damage estimation. However, 
since the design criteria and construction specification for buried pipelines in Korea and the US are different, the earthquake damages to pipelines in Korea using the pipeline RR recommended in HAZUS was reevaluated with the degree of confidence when RR is used without modification for the damage estimation of pipelines in Korea.

The numerical analyses using a commercial finite element model, ABAQUS (2006), were carried out to compare stresses and strains mobilized in buried pipelines constructed by the design criteria and construction specifications of both Korea and the US. The numerical results show that differences in the stress and strain rates are less than $10 \%$. This implies that RR in HAZUS can be used for earthquake damage estimation of pipelines with a $90 \%$ confidence level in Korea.

Acknowledgements. This work was supported by the INJE Research and Scholarship Foundation in 2011.

Edited by: B. D. Malamud

Reviewed by: two anonymous referees

\section{References}

ABAQUS Inc: Analysis user's manual, version 6.6, Hibbit, Karlsson \& Sorensen, Inc., Pawtucket, RI, 2006.

COSMOS, Peak Ground Acceleration Records, available at: http: //db.cosmos-eq.org, last access: 10 December 2010.

FEMA: HAZUS99 Technical Manual. National Institute of Building Science, Washington, DC, 1999.

Filho, O. A., Hirai, J. N., Oliveira, A. S., and Liotti, E. S.: GIS applied to geotechnical and environmental risk management in a Brazilian oil pipeline, Bull. Eng. Geol. Environ., 69, 631-641, 2010.

Jeon, S.-S.: Earthquake performance of pipelines and residential buildings and, rehabilitation with cast-in-place pipe lining systems, School of Civil and Environmental Engineering, Cornell University, Ithaca, New York, 2002.

Jeon, S.-S. and O'Rourke, T. D.: Northridge earthquake effects on pipelines and residential buildings, Bull. Seismol. Soc. Am., 95, 1-25, 2005.

Lee, D. H., Kim, B. H., Lee, H., and Kong, J. S.: Seismic behavior of a buried gas pipeline under earthquake excitations, Eng. Struct., 31, 1011-1023, 2009.
Ministry of Environment, Standard of wastewater facility, Korea Water and Wastewater Works Association, Seoul, Korea, available at: http://www.kwwa.or.kr/reference/devlop02_list.php, last access: 5 October 2010a.

Ministry of Environment, Standard of water facility, Korea Water and Wastewater Works Association, Seoul, Korea, available at: http://www.kwwa.or.kr/reference/devlop01_list.php, last access: 5 October 2010b.

Ministry of Land, Transport, and Maritime Affairs, Road Act, Seoul, Korea, available at: http://mltm.go.kr/USR/ordinance/m_ 15019/1st.jsp, last access: 5 October 2010.

Office of Pipeline Safety Community (OPS), Pipeline Safety Act, Washington, DC, available at: http://ops.dot.gov.regulations, last access: 12 September 2010.

O'Rourke, M. J. and Ayala, G.: Pipeline damage due to wave propagation, J. Geotech. Eng., 119, 1490-1498, 1993.

O'Rourke, M. J. and Liu, X.: Response of buried pipelines subject to earthquake effects, Monograph No. 3, Multidisciplinary Center for Earthquake Engineering Research, Buffalo, NY, 33-57, 1999.

O'Rourke, T. D., Toprak, S., and Sano, Y.: Factors Affecting Water Supply Damage Caused by the Northridge Earthquake, Proceedings of 6th US National Conference on Earthquake Engineering, Seattle, WA, 1-12, 31 May-4 June 1998.

Park, D., Yun, K., Chang, C.-J., Choi, W.-H., and Lee, D.-S.: Ground motion evaluation from the Fukuoka earthquake, J. Korean Geophys. Soc., 8, 109-113, 2005 (in Korean).

Pineda-Porras, O. and Ordaz, M.: A new seismic intensity parameter to estimate damage in buried pipeline due to seismic wave propagation, J. Earthquake Eng., 11, 773-786, 2007.

Scandella, L. and Paolucci, R.: Earthquake induced ground strains in the pressure of strong lateral soil heterogeneities, Bull. Earthquake Eng., 8, 1527-1546, 2010.

Shih, B.-J. and Chang C.-H.: Damage survey of water supply systems and fragility curve of PVC water pipelines in the Chi-Chi Taiwan earthquake, Nat. Hazards, 37, 71-85, 2006.

Takada, S. and Tanabe, K.: Three-dimensional seismic response analysis of buried continuous or jointed pipelines, J. Pressure Vessel Technology, 109, 80-87, 1987.

Tan, R. Y. and Chen, S. M.: The performance of water transmission systems under seismic loadings, Soil Dynam. Earthq. Eng., 6, 149-157, 1987.

Toprak, S. and Taskin, F.: Estimation of earthquake damage to buried pipelines caused by ground shaking, Nat. Hazards, 40, 124, 2007.

Wang, L. R.-L. and Cheng, K.-M.: Seismic response behavior of buried pipelines, J. Pressure Vessel Technology, 101, 21-30, 1979. 